\title{
Working at the Boundary: An Empirical Study into the Goals and Strategies of Knowledge Brokers in the Field of Environmental Governance in the Netherlands
}

\author{
Wynanda I. van Enst ${ }^{1, *}$, Peter P. J. Driessen ${ }^{1}$ (D) and Hens A. C. Runhaar ${ }^{1,2}$ \\ 1 Copernicus Institute of Sustainable Development, Environmental Governance Group, Faculty of \\ Geosciences, Utrecht University, Utrecht 3584 CS, The Netherlands; p.driessen@uu.nl (P.P.J.D.); \\ h.a.c.runhaar@uu.nl (H.A.C.R.) \\ 2 Forest and Nature Conservation Policy Group, Wageningen University and Research Centre, \\ Wageningen 6700 AA, The Netherlands \\ * Correspondence: w.i.vanenst@uu.nl
}

Received: 24 August 2017; Accepted: 16 October 2017; Published: 27 October 2017

\begin{abstract}
There is a broad range of literature on individuals who mediate at the boundaries between science and policy. However, there seems to be little empirical evidence on the goals and strategies of knowledge brokers, even though they appear to be becoming increasingly important in the field of environmental science and policy. This paper aims to improve the understanding of why and how knowledge brokers operate through an analysis of 27 in-depth interviews. It demonstrates that they see themselves as (strategically) sensitive to all stakes and stakeholders involved, possess a large network, and act without interests. They appear to act strategically in two different settings: on stage, where the collaboration of all stakeholders is needed, and backstage, where the knowledge broker steers the process on his/her own. Furthermore, our research suggests that the (perceived) credibility and legitimacy of the knowledge broker is more important to the process than the degree of credibility and legitimacy of the knowledge used in the decision-making process, and that it would be advisable to deploy knowledge brokers proactively, instead of reactively, which could lead to 'incident politics'.
\end{abstract}

Keywords: knowledge broker; science-policy interfaces; strategies; environmental policy-making

\section{Introduction}

In the field of sustainable development, the use of scientific knowledge is considered essential for understanding complex environmental problems such as climate change and biodiversity loss, identifying effective measures to address these problems, and informing environmental policy-making [1-5]. However, as Van Kerkhoff and Lebel [6] argue, the use of scientific knowledge is neither sufficient nor self-evident. The use of science in decision-making about environmental problems appears to be complicated, especially in situations with high levels of conflict among stakeholders, and where there are controversies surrounding environmental issues, e.g., [7-9]. In such situations, scientific knowledge can be strategically used, or selectively presented, either by scientists or by policymakers $[10,11]$. These difficulties have been well recognised in the scientific literature on (among others) environmental governance. Science-policy interfaces (SPIs) are often discussed in relation to these interaction problems as being possible 'solutions' [4,12]. In this context, SPIs are to be understood as processes, organisations, or individuals that "encompass relations between scientists and other actors in the policy process, and which allow for exchanges, co-evolution, and [the] joint construction of knowledge with the aim of enriching decision-making" [12] (p. 807). Another term 
often used for these strategic practices is that of 'boundary work' [13-15]. This paper will discuss individuals who engage in boundary work [16-19], and the ways in which they aim to overcome problems in science-policy interactions. The literature predominantly conceptualises these individuals, who focus on processes to improve the use and production of scientific knowledge in policy and decision-making, as 'knowledge brokers' [17,19-24]. However, even though the scholarly literature on boundary work and these individual mediators discusses goals and strategies [21,22,25,26], little empirical research appears to have been done on how these knowledge brokers address issues and processes concerning the interactions between science and policy in practice. Understanding which type of science-policy interaction problems knowledge brokers address, by means of what goals and strategies, and understanding their competences and capabilities, could yield more insight into how and when knowledge brokers should or could be deployed in a policy-making process.

This paper therefore presents exploratory research into knowledge brokers, the science-policy interaction problems they address, and their goals and strategies specifically within the Dutch environmental governance arena. This is a realm in which issues such as conflicts between economic development and nature conservation, for example, predominantly occur in a regional or national context [27-29]. We address the research question: how do knowledge brokers perceive the interactions between science and policy, and how do they define their role in terms of goals and strategies, to improve the production and use of science in policy and decision-making? For this research, we understand 'knowledge brokers' to be a theoretical concept, which will be researched empirically in terms of institutional diversity, goals, and strategies, in order to achieve further theoretical depth.

To answer the research question, first, the general concept of 'boundary work' will briefly be clarified, followed by the main theoretical characteristics of knowledge brokers. The third section will explain the methodology used during the empirical research. The fourth section will present the empirical findings, including a typology of knowledge brokers. Finally, in the last section, we will present our reflections, conclusions, and points for discussion.

\section{Boundary Work and Knowledge Brokers: A Brief Literature Review}

\subsection{Boundary Work}

The concept of boundary work finds its origin in the work by Gieryn, who discusses the active management of the socially constructed boundary between science and policy as the utility of boundary work [13]. The need for boundary work rises from tensions that arise "at the interface between communities with different views of what constitutes reliable or useful knowledge" [30] (p. 4615). Clark et al. [30] argue that in the case of an impermeable boundary, no communication can take place across it. On the other hand, if a boundary is too porous, science might get mixed with politics, which would decrease the value of research-based knowledge. In more general terms, Van Enst et al. argue that there are three types of meta-problems related to interactions between science and policy: (i) the strategic use of knowledge; (ii) the strategic production of knowledge; and (iii) the operational misfit between the demand for, and supply of, knowledge [9]. Boundary work, in those cases, is required to construct and manage the interactions among various stakeholders, or communities, with the aim to lead to more productive and informed policy-making [31]. The scholarly literature on boundary work is expanding, addressing the concept from different perspectives [25,31-36]. In general, however, three functions can characterise boundary work: (i) communication-active, iterative and inclusive; (ii) translation-facilitating mutual understanding between experts and decision-makers, eliminating the hindrance of jargon, language, experiences, and presumptions; and (iii) mediation-enhancing the legitimacy of the process by increasing transparency, bringing all perspectives to the table, providing rules of conduct, and establishing criteria for decision-making [26]. By means of these functions, boundary work, carried out by knowledge brokers for example, should lead to creation of credible, legitimate, and salient knowledge: knowledge that is scientifically adequate, accurate, and trustworthy; 
reflects and respects the divergent beliefs and values of stakeholders; is seen as free from bias; and is considered to be relevant to decision-makers and the problem at stake $[8,26,37]$.

\subsection{Knowledge Brokers as Boundary Workers}

In regards to conducting boundary work, the reviewed scholarly literature refers to different typologies of boundary workers, ranging from boundary-spanning individuals who are often part of an organisation on one side of the boundary (e.g., [32,38], to people who aim to connect science and policy (and scientists and policy makers) by either acting as "intermediaries between researchers who produce knowledge, and policy makers who are prospective consumers of that knowledge" [23] (996), or by attempting to overcome the boundaries between science and policy by facilitating the creation, sharing, and use of knowledge. The latter type of boundary workers, to which the literature refers to as 'knowledge brokers', will be central in this paper.

Despite slight differences in the characteristics of knowledge brokers presented by various authors $[16,17,39]$, what these individuals appear to have in common is a degree of neutrality, impartiality, authority, and the ability to build bridges between science and policy, due to their own cross-sector experiences. Considering their institutional backgrounds, the reviewed literature tends to describe knowledge brokers as academics $[16,23,24]$, although there are also references to policy makers [21] and to private sector individuals $[10,17]$ acting as knowledge brokers. In terms of their goals and strategies, knowledge brokers are expected to "expand the scope of choice available to decision-makers" [16] (p. 17), facilitate interactions, and supply, translate, and link knowledge to and between different contexts [19,24,39,40]. Additionally, Cash et al. [26] argue that knowledge brokers should enable the production and use of knowledge that is (perceived to be) credible, legitimate, and salient. Eventually, this should lead to enriched decision-making processes. These goals are to be reached by mean of strategies, which are conceptualised following Mintzberg as a "consciously intended course of action, a set of guidelines to deal with a situation ( . . ) [with] two essential characteristics: they are made in advance of the actions to which they apply, and they are developed consciously and purposefully" [41] (p. 11). However, on the subject of strategies, the scholarly literature on knowledge brokers appears to be less concrete. Moss et al., for example, describe the 'hidden role' of knowledge brokers, by distinguishing three dimensions: (1) the opening up of relationships, or mediating, between production, consumption, and regulation; (2) working between different scales, or levels, of action, e.g., challenging existing hierarchical forms of governance to bring local agendas into the policy realm; and (3) working between technologies and social contexts, e.g., presenting technologies in such a manner (translated) that it speaks to all parties involved [39] (pp. 24-25). However, these dimensions still shed no light on how knowledge brokers go about these actions.

\subsection{Conclusions}

Based on the previous discussion, we draw the following conclusions. Firstly, the use of knowledge brokers to manage, and even overcome, the boundary between science and policy appears to be self-evident. However, little in depth analyses are made regarding how strategies such as 'facilitating', 'negotiating', or 'mediating' are operationalised. Secondly, although references to different institutional backgrounds of knowledge brokers can be found, to what extent these different backgrounds influence the goals and strategies of these individuals remains inexplicit. With this study, we aim to further explore these issues.

\section{Methods}

\subsection{Interviewee Selection}

We based our interviewee selection on the following: first, in the field of environmental governance in the Netherlands, the need for knowledge brokers appears to be most pressing in cases in which scientific knowledge is highly disputed, and where there are many conflicting interests. 
Therefore, cases of this type could lead to the identification of knowledge brokers. Secondly, the interviewee should have a certain amount of cross-sector experience (science and policy) [17,39]. Finally, an equal distribution of institutional backgrounds (science, policy, and consultancy) among the interviewees was sought after. In selecting our interviewees, these considerations served as a guide: they were more applicable to some persons than to others.

Taking the above into account, we first selected the key figures who executed the role of knowledge broker in well-known and well-documented cases in the Netherlands in which there was controversy about the role of scientific knowledge in (national) environmental policy development and decision-making processes (To ensure the anonymity of our interviewees, we are not able to provide too many substantive details on specific cases). For example, we interviewed a knowledge broker with a background in policy, who held a mediating position in the discussion on the gas extraction and cockle fishery activities in the Wadden Sea, and another who was involved in knowledge production for the transition towards sustainable mussel fishery in the Wadden Sea. Secondly, we selected individuals who held a key position as a knowledge broker, and identified themselves as such, within Dutch ministries and large governmental programmes and organisations that focus on environmental issues. For example, we interviewed a former Chief Scientist of a Dutch Ministry on his daily activities, which included informing senior policy makers and ministers. Another interviewee held the position of knowledge broker within the Dutch Delta Programme, a governmental programme responsible for water management in the Netherlands. Thirdly, we selected private sector consultants, or advisors, who specialised in facilitating processes between science, environmental policy makers, and other stakeholders. Finally, by means of snowball sampling, other interviewees were identified. This method also provided validity and verification, since the people suggested were often already on our list of interviewees. In total, this yielded 27 knowledge brokers with a range of institutional backgrounds: nine interviewees with a scientific background, nine interviewees with a background in policy, and finally nine private sector consultants, or advisors. To mention a few, we interviewed university professors who also had (or had had) very senior positions in the Dutch government and ministries, entrepreneurs, representatives of (large) consultancies, and knowledge brokers who worked either in a governmental organisation or in a research organisation whose remit is to inform a Dutch ministry. Although the cases discussed during the interviews showed resemblances, such as in terms of policy field (environmental policy), level (predominantly national), and complexity (multi-stakeholder, multi-interest), none of the interviewees discussed similar cases. In addition, we wish to stress that we are aware that our list of interviewees is not exhaustive, but we do believe it covers a broad range of knowledge brokers within the Dutch national environmental governance arena.

\subsection{Data Collection and Analysis}

Our aim was to understand which type of science-policy interaction problems knowledge brokers address, what goals and strategies they used, and what competences and capabilities they applied. Our data collection was structured accordingly. First, we addressed the competences and characteristics of a knowledge broker. Secondly, we discussed the different empirical goals knowledge brokers have, and thirdly, in relation to these goals, their used strategies. Finally, since the literature suggested that knowledge brokers' institutional backgrounds influenced goals, strategies, competences, and capabilities (see Section 2.2), we also addressed the type of science-policy interaction problems the interviewees came across during the empirical research. We added this in order to possibly establish whether a knowledge broker with an institutional background in science might address different science-policy interaction problems than a knowledge broker with a private sector background.

Our data collection consisted of semi-structured interviews. Prior to the interviews, all of the interviewees were sent a topic list consisting of five questions that would be the main themes for the interview. We based both the topic list and the questionnaire (see the supplementary material) that guided the interviews on the conceptual framework presented in Section 2. As we interviewed the knowledge brokers, but not the stakeholders who were involved in the boundary working processes, 
the answers the interviewees provided us with are self-perceived. Finally, with the consent of the interviewees, all of the interviews, which were conducted in Dutch, were recorded and transcribed.

Using Nvivo software, the transcribed interviews were coded for qualitative data analysis. The first part of the analysis was based on deductive coding [42]. On the basis of the different concepts in the conceptual framework, a list of categories was developed prior to the data analysis. Subsequently, verbatim quotes from the interviews were assigned to these different categories. Per category, this resulted in a list of quotes originating from different interviews. The second part of our analysis was based on inductive coding: using the quotes in each category, we developed sub-clusters in order to systematically categorise the coded transcripts. For example, the interviewees were asked to describe certain competences that they thought knowledge brokers ought to have, which resulted in over 200 quotes for that question. Analysing these quotes, we came across remarks (which we have translated for this paper) such as 'I had status', 'on both sides I was respected and had authority', 'at a certain point you have a voice, and that voice becomes authoritative'. These three quotes were clustered into the code 'power, authority', based on the choice of words and their explicit meaning. As another example, the interviewees were also asked which interaction problems between science and policy they encountered during their work. This question resulted in over 100 quotes. Analysing this list yielded quotes such as 'everyone works on the problem from their own perspective', 'the guidance from policy to science is lacking', and 'they [scientists] say that policymakers are not interested in knowledge, but that is not true. However, they do not realise that knowledge $(\ldots$ ) can be difficult. They need to provide clarity'. These were clustered into the interaction problem 'cultural differences between the world of science, and the world of policy', based on the (sometimes less explicit) references to cultural differences, e.g., different perspectives and backgrounds, or a different understanding of what is needed in the process. We are aware that this methodology might have its limitations, as researcher bias might influence the interpretations of the verbatim quotes. However, by explicitly demonstrating how we approached the analysis, and supporting the results with verbatim quotes from the interviews (translated from Dutch to English) and including the questionnaire in the supplementary material, we aim to be transparent about our methodology and analysis. On a final note, we wish to stress that it is not the aim of this paper to present a quantitative analysis. However, in our analysis, we did also pay attention to the distribution of answers between the knowledge brokers with different institutional backgrounds in order to discover to what extent a person's institutional background might influence their goals and strategies.

\section{Results}

We analysed the empirical data on four categories discussed above in the literature overview on knowledge brokers. Firstly, the science-policy interaction problems knowledge brokers address are discussed, in order to better understand the situations in which knowledge brokers operate. Secondly, their goals are discussed, followed by the strategies they use. Finally, their self-perceived competences and capabilities are presented. In this section, each of these categories will be explored in two ways. First, in general: after analysing all of the interview data, we created sub-categories, at this stage making no distinction between 'who said what'. Second, we determined whether there were noticeable differences between knowledge brokers with different institutional backgrounds (science-related knowledge brokers, policy-related knowledge brokers, and consultants). The results of the four categories are presented in four figures, displaying the cumulative amount of knowledge brokers who addressed a specific sub-category, but also to what extent this sub-category was discussed by the knowledge brokers with different institutional backgrounds.

\subsection{Science-Policy Interaction Problems Addressed}

The interviewees discussed a wide range of issues that (according to them) caused problems regarding the interactions between science and policy, and as a result complicated the use of science in policy and decision-making processes. Based on the interviews, which generated over 100 statements, 
four types of problems can be defined (for a full explanation of these interactions problems, we refer to the supplementary material), as is shown in Figure 1.

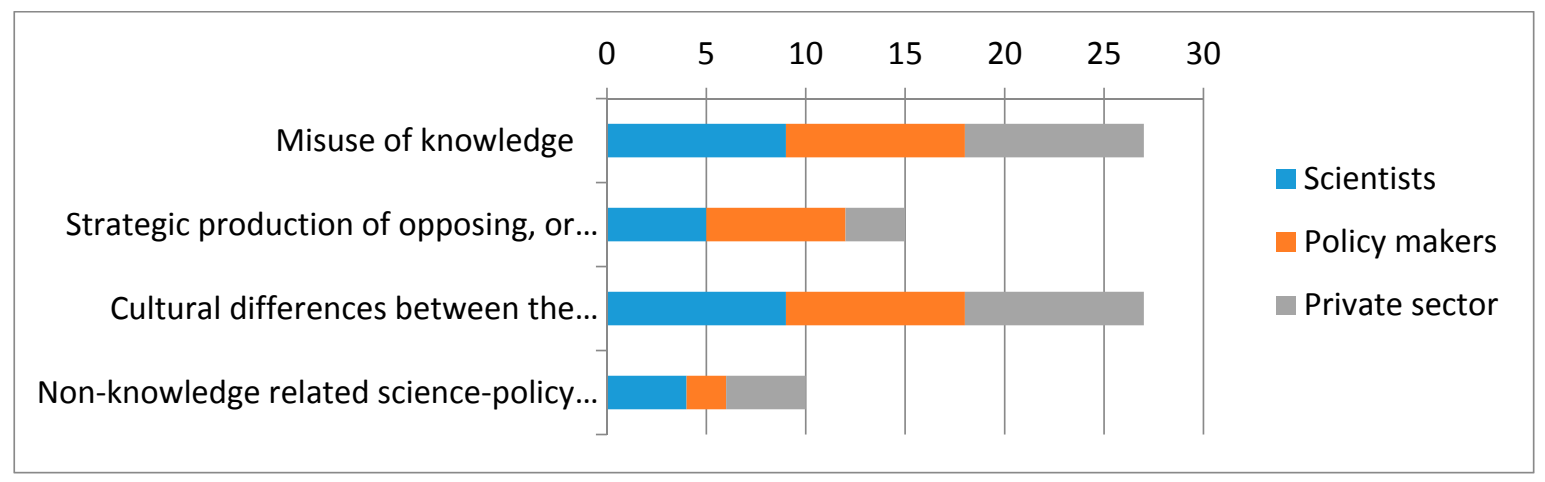

Figure 1. Science-policy interaction problems mentioned during interviews, categorised per knowledge broker 'type' and quantified accordingly.

First, all of the interviewees discussed the misuse of knowledge. This interaction problem was addressed by means of empirical examples in which contra-expertise was used to discredit scientific reports, situations in which knowledge was used to support pre-set policy, and cases where knowledge was ignored. Relating the latter, one interviewee explained, for example: "It depends on the culture of the department, but knowledge from outside is perceived as inconvenient, to put it bluntly. When a university or research institute produced a report in the field of [the department] sometimes a sigh was heard: 'and now we have to do something with it'. It was not experienced as helpful'". (PM4)

Secondly, all of the interviewees recognised problems related to cultural differences between science and policy; these problems arose because of differences in terms of discourses, culture, levels of abstraction, and notions of time. Also discussed were problems with the formulation of policy and research questions by policy makers that were due to insufficient active steering from policy towards science, and to policy makers' reluctance to seek clarification by asking questions. To give an example: one interviewee explained that he "asked the scientists questions because the policy makers did not dare to do so. ( ... ) They didn't feel safe enough. They felt like their academic background was too limited to ask the proper questions". (S2)

Thirdly, most of the knowledge brokers we interviewed addressed issues concerned with the strategic production of opposing, or incomplete knowledge, such as the production of incomplete knowledge due to a lack of collaboration and co-creation, or situations in which research was conducted out of academic interests rather than driven by policy questions.

Finally, science-policy interaction problems transcending knowledge were mentioned. One of our interviewees explained: "Most of the time you get involved because people are done talking to each other. In Dutch, we say 'trust comes by foot, and leaves on horseback'. In this case, all of the horses ran in different directions. Every conversation between stakeholders ended within minutes, with threats of lawsuits. They were done talking". (C5)

Based on the foregoing, it is especially interesting to see that the problems knowledge brokers address are far from exclusively knowledge-related. Where the scholarly literature on SPIs and knowledge brokers predominantly emphasises the problematic (mis)use and (mis)production of knowledge, this empirical research suggests that besides these problems, knowledge brokers are also confronted with a variety of issues that, at first sight, have no relation to knowledge, but which do have a negative influence on the use of science in policy and decision-making processes. It could, however, be hypothesised that underlying these issues, which appear to focus on the inter-relational aspect of interactions, is the problematic production and use of knowledge. As the interviewees explained, it is necessary to solve these interaction problems first in order to then be able to focus on the interaction problems related to the production and use of knowledge. 
Finally, based on the analysis presented in Figure 1, two additional remarks can be made. First, the strategic production of knowledge appears to be a problem predominantly discussed by the interviewees with a policy background; scientists discussed the strategic production of knowledge to a lesser extent. This strategic behaviour is often addressed in the literature on science-policy interactions: for example, Strydom et al. [43] argued that scientists keep science out of reach of policy makers in order to ensure that they retain their control on the interpretation of science. If policy makers experience this the most, it is hardly surprising that these knowledge brokers emphasise this issue. On the other hand, scientists and consultants discuss problems that are not limited to knowledge more often by than policy makers. The reason could be that the interviewed knowledge brokers from the private sector, for example, tend to be brought into a process to solve whatever interaction issues there might be, whether or not these are to do with the use and production of knowledge.

\subsection{Goals of Knowledge Brokers}

The interviewees' responses to the questions relating to their goals yielded close to 75 statements. These were inductively combined into three main goals (for a full explanation of these goals, we refer to the supplementary material), as presented in Figure 2.

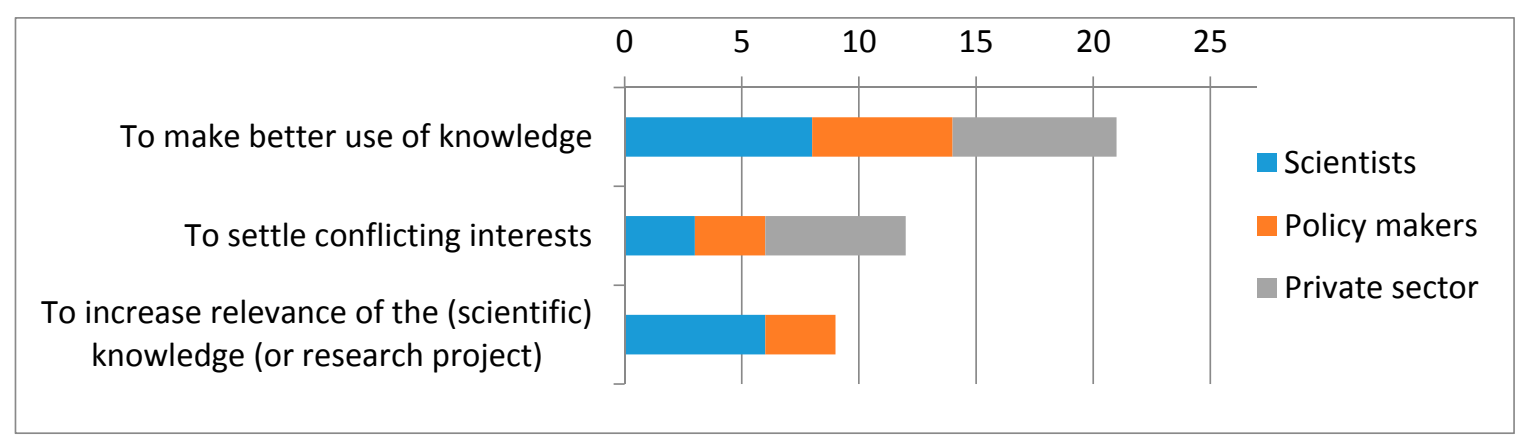

Figure 2. Goals of knowledge brokers, mentioned during interviews, categorised per knowledge broker 'type' and quantified accordingly.

Firstly, the interviewed knowledge brokers claimed that their aim was to allow knowledge to be used better in decision-making processes. This first goal is in line with the literature review on boundary work presented earlier in this paper: facilitating the production, sharing, and use of science in order to enrich decision-making processes is at the core of the theory on boundary work and knowledge brokers $[2,12,17,26,44]$. By increasing the credibility, legitimacy, and salience of the knowledge produced, the aim is to provide the stakeholders with all of the opportunities they need to be able to use the knowledge properly. This was expressed by one of our interviewees as follows: "Before my arrival, people here stood with their backs turned away from policy. It [policy] was unreliable, dangerous, even though we worked as a public service. ( . . ) I came here because I wanted things to be different, because I wanted to increase the relevance of this institute and make all this expertise useful for society (...) create impact" (PM3).

The second goal, which was predominantly mentioned by the interviewees from the private sector, concerns the resolving of conflicts or conflicting interests between stakeholders that would otherwise cause an impasse in the interaction process. It was suggested that disputes occur not only between scientists, policy makers, and other stakeholders, but also within these stakeholder groups, for example, between scientists with different fields of expertise. To illustrate this, one of our interviewees explained a situation in which "the province strongly dictated [the process] from its own perspective on what needed to happen. The other stakeholders felt left out. Thus far it was plain common process management between different stakeholder groups" (C1). This goal has received less attention in the reviewed scholarly literature, especially in relation to a possible link between it and the institutional 
background of the knowledge broker. The resolution of conflicting interests could be situated in the debate on knowledge utilisation in which the institutional and cultural differences between science and policy are discussed together with how collaboration could solve these issues [8], for example, since these issues often result from institutional and cultural differences. However, in the theory discussed here, this is not articulated as such.

The third and final goal presented here concerns the involvement of knowledge brokers to increase the relevance of a project or programme. The empirical research suggests that the intervention of the knowledge broker should ultimately enhance the social and scientific relevance of the programme in question. In concrete terms: by becoming involved, the knowledge broker personally increases the relevance of a research programme or organisation. This means that this goal has a different origin than the other two. The first two goals could be considered to be personal goals, or goals that need to be reached by means of the intervention of the knowledge broker. However, this last goal reflects the goal of the initiator of the process. The interviewees who discussed this goal, who were predominantly knowledge brokers with a scientific institutional background, stated that their particular intervention was used strategically: their involvement, contribution, and status as scientists were used to legitimise the social and scientific quality of the particular project, and to enhance its credibility. It could be hypothesised that regarding this last goal, these particular knowledge brokers did not 'work at the boundary'; rather, they themselves were the 'boundary work'. By this, we mean that their involvement already enhanced the interactions between science and policy, rather than referring to the way in which they acted.

\subsection{Strategies Used by Knowledge Brokers}

Over 300 statements referring to the strategies used were inductively combined into nine general strategies (for a full explanation and operationalisation of these strategies, we refer to the supplementary material), which are presented in Figure 3.

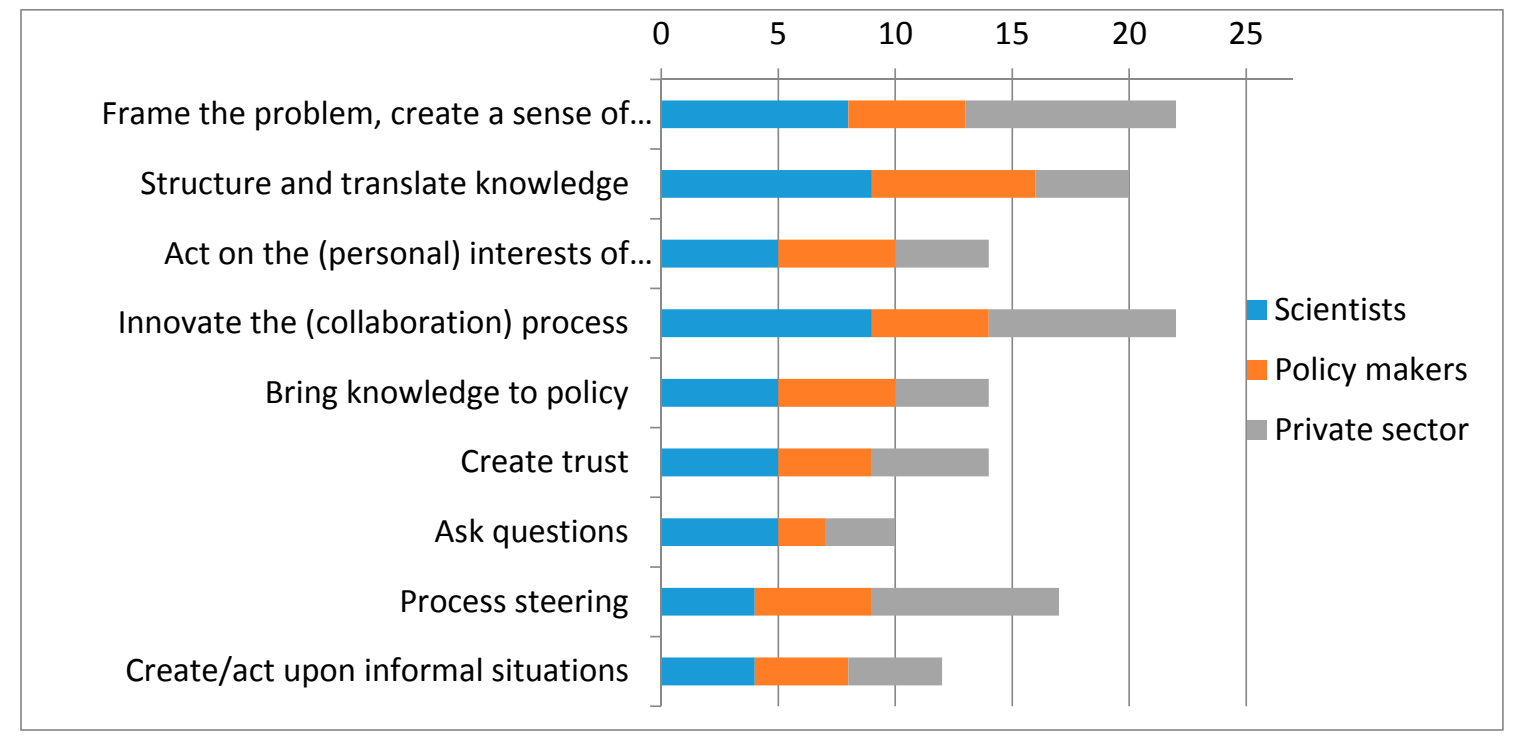

Figure 3. Strategies of knowledge brokers, mentioned during interviews, categorised per knowledge broker 'type' and quantified accordingly.

The nine strategies discussed by the interviewed knowledge brokers, and as presented in Figure 3, give rise to the following analysis. Knowledge brokers appear to use two types of strategies. The first type concerns strategies that address the more factual side of boundary work: the framing of the problem. For example, this could include forcing stakeholders to approach the problem at hand and propose a solution from an opposing perspective, which could lead to mutual understanding of 
other standpoints in the debate. This type also includes the structuring and translating of knowledge. For example, one of the interviewees explained that he would create a one-page document that summarised a scientific report, and then distribute it within the Ministry in which he worked. He argued that due to his extensive experience in the field of policy-making, and his knowledge of which dossiers were relevant to his department, he could singlehandedly decide which scientific report would be translated and summarised into this one-page document, and which would not. The knowledge broker thus tried to proactively create awareness, understanding, and acceptance of the available scientific knowledge. Other strategies included bringing knowledge to policy, for example by means of the 'knowledge at the table' principle, and asking questions.

The second type of strategies is concerned with the process side of the boundary work. Ways in which a knowledge broker can influence the interaction process include taking deliberate actions to enhance the interaction process, e.g., choosing the first speaker during a meeting strategically, to set a positive tone. They can also include actively changing roles and wearing different hats to help the process more forward, e.g., shifting strategically between rationales: each stakeholder has their own rationality, and using a policymaker's rationale when addressing a scientist does not work. Knowledge brokers can also strategically steer a process into another direction when a mediation process has reached an impasse. For example, this latter strategy was illustrated by an interviewee who explained that in some cases, he as a knowledge broker foresaw the process coming to a dead end for various reasons (e.g., lack of credible knowledge, wrong questions asked). However, it was not possible to intervene until all of the stakeholders also understood that the process would stall. Active steering to create this awareness was needed in order to guide the process into another direction.

However, the foregoing immediately raises the question of whether the intervention of a knowledge broker is focussed solely on bringing scientific knowledge to policy (and policy practices), and bringing policy questions to science, or whether process-oriented results are more important. From the distribution of strategies used in relation to the different knowledge brokers, as can be seen in Figure 3, it seems that knowledge brokers from the private sector place more emphasis on the process side of boundary work than scientists and policy makers do when they act as knowledge brokers. Perhaps this is because these private sector knowledge brokers become involved in highly unstructured problems, such as societal problems for which there is no definite solution and where decisions are often based on a range of values and interests of the stakeholders involved. The level of structuredness is (according to Hoppe [35]) based on the level of reliability of relevant knowledge, and on the level of consensus about relevant norms and values. If neither of these two is applicable to a policy problem, it can be considered to be 'unstructured'. This hypothesis would be in line with the results discussed in the previous sections, since this group of knowledge brokers also identified interaction problems not limited to knowledge as an interaction problem, and claimed that settling conflicts and conflicting interest was at the heart of their work as knowledge brokers.

\subsection{Essential Competences, Qualities and Capabilities of Knowledge Brokers}

Having discussed the interaction problems on which knowledge brokers focus, as well as their goals and strategies, the final question that remains concerns the knowledge brokers as persons. What competences, qualities, or capabilities do they have that enables them to act as knowledge brokers? The interviewees were therefore asked to define the competences, qualities, and capabilities that they thought a knowledge broker should have. This question generated over 200 statements, which resulted in the 10 categories (for a full explanation of these competences, we refer to the supplementary material) that are presented in Figure 4. 


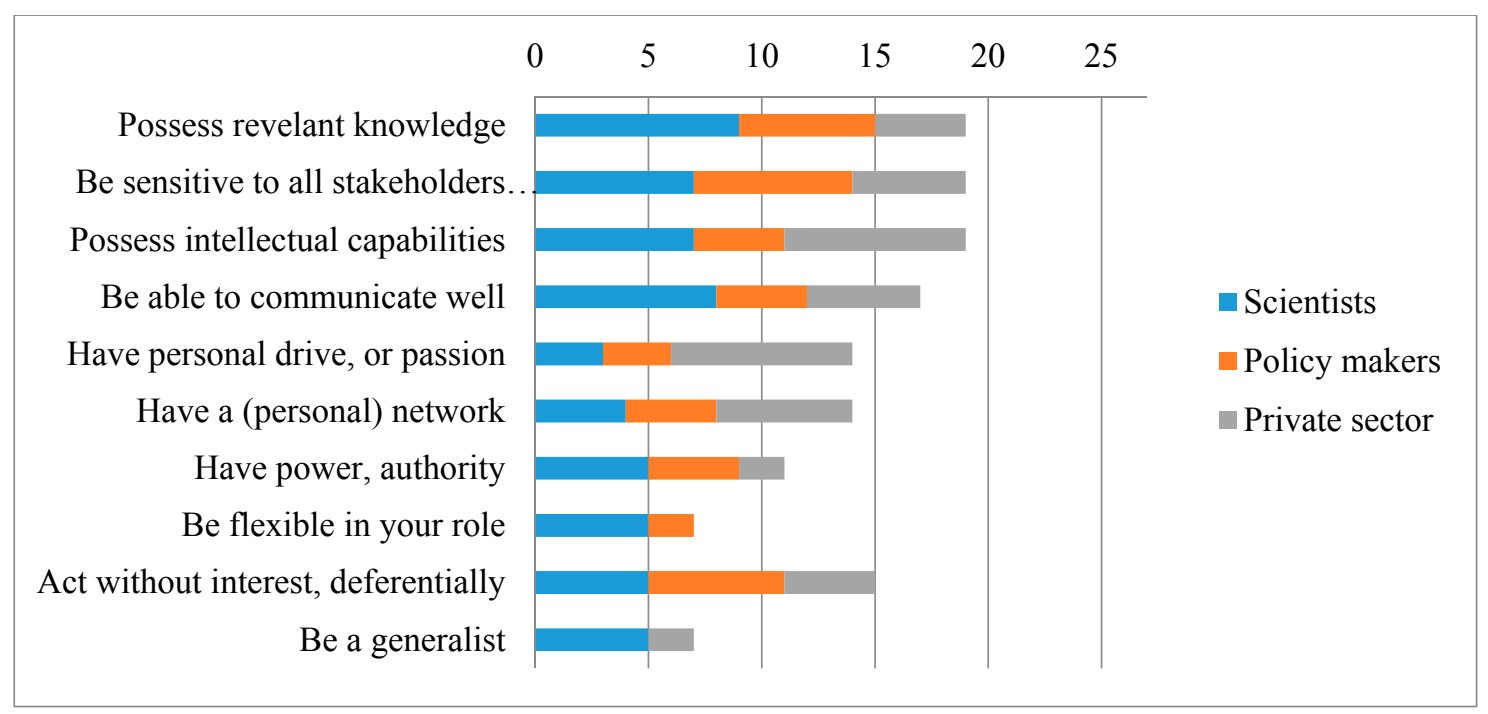

Figure 4. Competences, qualities, and capabilities of knowledge brokers mentioned during interviews, categorised per knowledge broker 'type' and quantified accordingly.

As can be seen in Figure 4, seven competences, qualities, and capabilities can be identified as having been discussed by the majority of the interviewees. In terms of competences, having a personal network, being in the possession of relevant knowledge (both process and factual knowledge), and possessing intellectual capabilities, or, as one of the interviewees stated: "You need to be a systems thinker, capable of finding the coherence of things" (S6), are considered to be important. In terms of personal qualities, being aware of and acting upon the different interests of the participants in the process, and having a personal drive to do this type of work were suggested to be essential. Finally, regarding useful capabilities, over half of the interviewees mentioned the ability to communicate well and to act impartially. The outcome is not surprising, given the goals and strategies of these individuals and the work they do.

Noteworthy differences between the three categories of knowledge brokers can be seen in their motivation of 'having a drive and commitment'. This was mostly discussed by interviewees from the private sector: terms like 'passion', 'commitment', and 'sincere interest' cropped up during the interviews, but were not elaborated upon. A possible reason for this predominance of private sector interviewees is that the consultants interviewed act as knowledge brokers on a daily basis-it is their job-whereas the scientists interviewed, for instance, often had many other responsibilities. Additionally, as one interviewee argued, in academia you are judged on achievements other than acting as a knowledge broker. The final interesting difference regards the last competence: being a generalist. This was predominantly mentioned by scientist interviewees. The reason for this might be that a scientist knowledge broker often becomes involved due to his/her own field of expertise. However, in the case of contentious knowledge and conflicting interests, multiple fields of science interact. For scientists, this could therefore result in being aware of their 'generalist qualities'.

\section{Discussion and Recommendations}

This research originated from our interest in better understanding how knowledge brokers perceive the interactions between science and policy, and what their goals and strategies are to improve the production and use of science in decision-making processes. Based on the analyses presented in the previous section, we can firstly conclude that this research adds another category to the existing framework on science-policy interaction problems: that of interaction problems not limited to knowledge, which hamper the interactions between science and policy, but are not directly linked to the use or production of knowledge. Secondly, the goals of the interviewed knowledge 
brokers are far from exclusively focussed on enhancing the use and production of knowledge. Contrary to what the literature overview presented earlier suggests, the goals discussed by our interviewees also point to the resolving of conflicts between stakeholders. Getting stakeholders to communicate with each other appears to be a dominant goal, especially for the interviewees from the private sector. This brings us to a third conclusion: the institutional background of a knowledge broker has implications for the science-policy interaction problems they address, as well as their goals and the strategies that they use. We have seen that especially knowledge brokers whose background lies in the private sector address interaction problems that are not limited to the issues related to the production and use of knowledge, and often have aimed for the different stakeholders to start communicating with each other. One of our interviewees (director of a small consultancy, specialised in the facilitation of multi-stakeholder processes in the field of environmental governance) argued that his work often comprised the management of people, instead of the brokering of knowledge. On the other hand, the interviewees with a scientific background, more than the other two categories, argued that they were involved in boundary work processes because their presence alone already increased the credibility and legitimacy of the knowledge development process. The observation that knowledge brokers with different institutional backgrounds address different science-policy interaction problems could hypothetically point to an interesting recommendation for practice. The success of enhancing science-policy interactions, with the ultimate aim to enrich decision-making processes might depend on the choice of knowledge broker in relation to the interaction problem at stake. Fourthly, based on the strategies discussed in the previous section, we made a distinction between strategies focussed on the process side of boundary work, and strategies that focussed on the substantive side of boundary work. However, another type of differentiation is also possible. It could be hypothesised that knowledge brokers work in two settings that require different types of strategies: one on stage, which involves different stakeholders, the other one backstage, where the knowledge broker him/herself strategically manoeuvres the process into a certain direction. The framing of the problem, but also actively bringing knowledge to policy and the creation of trust, are strategies that could fall under the first category (on stage): the collaboration of all stakeholders is needed to make these strategies useful and productive. Strategies related to the process side of boundary work, such as the strategic steering of the process and the creating of informal situations, could be described as backstage strategies: the knowledge broker foresees where the process needs to be steered, and tries to do so on his/her own. This perspective on the strategies of knowledge brokers makes the process of boundary work less transparent than the current scholarly literature discussed in this paper would have us believe.

So, what role does scientific knowledge have in all of these processes? Of all the competences and capabilities that emerged in the empirical results, the one that most interviewees mentioned as being the most important was the possession of knowledge on the topic on which they are working. However, based on the foregoing, it appears to be more likely that the (perceived) credibility and legitimacy of the knowledge broker is more important to the process than the degree of credibility and legitimacy of the knowledge used in the decision-making process. When comparing the (hypothetical) role of the honest broker (e.g., Pielke [16]) with the practical reality of the interviewed scientist knowledge brokers, this idea of presenting or focussing on incorporating credible knowledge into the interaction process to enrich decision-making processes is less dominant than might be expected. This does not mean that the intermediary processes these knowledge brokers are involved in do not focus on knowledge at all. As argued throughout this paper, the interactions between science and policy are often difficult because of the knowledge at issue-whether it is regarding its use or its production. However, this research suggests that a knowledge broker is needed not only when there are conflicts around knowledge. Or, as one of the interviewees puts it: 'I would always use an intermediary when [the process] is blocked, and yet there is enough knowledge and insight present to be able to develop alternatives, but due to resistance this has not been done. ( . . . ). The world of knowledge does not 
spread on its own, and the stakeholders involved are not at all interested [in this knowledge], since they want to keep their viewpoint. That is the ideal moment for a knowledge broker'.

We would argue that this research provides us with a next step in understanding the concept of knowledge brokers, both in theory and in practice. However, as with any research, this research has some limitations that need to be considered. First of all, we did not analyse in depth how the boundaries between science and policy were shaped, and by whom. Rather, we took this as the starting point of this explorative study. Future research could analyse in more depth how actors shaping the boundary contribute to the need for particular types of knowledge brokers on the boundary. Secondly, we are also aware that our sample of 27 is too small to give a complete and general answer on why and how knowledge brokers work in practice. Lastly, our geographical focus might also cause limitations: the Netherlands is known for its consensus culture, and this culture is likely to influence the strategies used by knowledge brokers within that setting.

We recommend further research into the actual effectiveness of knowledge brokers in enriching decision-making processes. More in-depth empirical research into single knowledge brokers is a suggestion. Focussing on the strategies of knowledge brokers in specific cases will provide more detailed accounts of how individual knowledge brokers work. Secondly, during the interviews, the interviewees discussed various situations in which they acted as knowledge brokers. Most of the interactions between science and policy in the situations discussed were already troubled at the time the knowledge broker intervened in the process. This comes across as 'incident politics': deploying knowledge brokers reactively, when the interaction problems already exist. Instead, we recommend starting a debate on the practice of environmental governance, regarding whether or not knowledge brokers should proactively be given a mediating role in complex decision-making processes from the beginning of the process. This is an important consideration since, as one of the interviewees stated, there does not need to be a science-policy interaction problem for there to be a need for a knowledge broker.

Supplementary Materials: The following are available online at www.mdpi.com/2071-1050/9/11/1962/s1.

Acknowledgments: We are grateful to the 27 respondents who were willing to participate in this research: for their interesting insights, and the valuable data they allowed us to generate during the interviews. Furthermore, we would like to thank the two anonymous reviewers for their valuable comments and suggestions. This research is part of the National Ocean and Coastal Research programme (ZKO) financed by the Netherlands Organisation for Scientific Research (NWO) and the Wadden Academy. Joy Burrough edited the English of a near-final draft.

Author Contributions: The research was designed by Wynanda van Enst, Peter Driessen and Hens Runhaar. Wynanda van Enst conducted the interviews, in some cases together with Hens Runhaar. Wynanda van Enst analysed the transcriptions with NVivo, all three authors were involved in the further analysis of the data. Wynanda van Enst wrote the paper, with substantial contributions by Hens Runhaar and Peter Driessen.

Conflicts of Interest: The authors declare no conflict of interest.

\section{References}

1. Cortner, H.J. Making science relevant to environmental policy. Environ. Sci. Policy 2000, 3, 21-30. [CrossRef]

2. McNie, E.C. Reconciling the supply of scientific information with user demands: An analysis of the problem and review of the literature. Environ. Sci. Policy 2007, 10, 17-38. [CrossRef]

3. Turnhout, E.; Hisschemöller, M.; Eijsackers, H. Ecological indicators: Between the two fires of science and policy. Ecol. Indic. 2007, 7, 215-228. [CrossRef]

4. Holmes, J.; Clark, R. Enhancing the use of science in environmental policy-making and regulation. Environ. Sci. Policy 2008, 11, 702-711. [CrossRef]

5. Van Enst, W.I.; Runhaar, H.A.C.; Driessen, P.P.J. Boundary organisations and their strategies: Three cases in the Wadden Sea. Environ. Sci. Policy 2016, 55, 416-423. [CrossRef]

6. Van Kerkhoff, L.; Lebel, L. Linking knowledge and action for sustainable development. Annu. Rev. Environ. Resour. 2006, 31, 445. [CrossRef]

7. Driessen, P.P.; Leroy, P.; Van Viersen, W. (Eds.) From Climate Change to Social Change: Perspectives on Science-Policy Interactions; International Books: Utrecht, The Netherlands, 2010. 
8. Hegger, D.; Lamers, M.; Van Zeijl-Rozema, A.; Dieperink, C. Conceptualising joint knowledge production in regional climate change adaptation projects: Success conditions and levers for action. Environ. Sci. Policy 2012, 18, 52-65. [CrossRef]

9. Van Enst, W.I.; Driessen, P.P.; Runhaar, H.A. Towards productive science-policy interfaces: A research agenda. J. Environ. Assess. Policy Manag. 2014, 16. [CrossRef]

10. Runhaar, H.; Van Nieuwaal, K. Understanding the use of science in decision-making on cockle fisheries and gas mining in the Dutch Wadden Sea: Putting the science-policy interface in a wider perspective. Environ. Sci. Policy 2010, 13, 239-248. [CrossRef]

11. Saarela, S.R.; Söderman, T. The challenge of knowledge exchange in national policy impact assessment-A case of Finnish climate policy. Environ. Sci. Policy 2015, 54, 340-348. [CrossRef]

12. Van den Hove, S. A rationale for science-policy interfaces. Futures 2007, 39, 807-826. [CrossRef]

13. Gieryn, T.F. Boundary-work and the demarcation of science from non-science: Strains and interests in professional ideologies of scientists. Am. Sociol. Rev. 1983, 48, 781-795. [CrossRef]

14. Guston, D.H. Boundary organizations in environmental policy and science: An introduction. Sci. Techol. Hum. Values 2001, 26, 399-408. [CrossRef]

15. Owens, S.; Petts, J.; Bulkeley, H. Boundary work: Knowledge, policy, and the urban environment. Environ. Plan. C 2006, 24, 633-643. [CrossRef]

16. Pielke, R.A. The Honest Broker: Making Sense of Science in Policy and Politics; Cambridge University Press: Cambridge, UK, 2007.

17. Meyer, M. The rise of the knowledge broker. Sci. Commun. 2010, 32, 118-127. [CrossRef]

18. Kinnie, N.; Swart, J. Committed to whom? Professional knowledge worker commitment in cross-boundary organisations. Hum. Resour. Manag. J. 2012, 22, 21-38. [CrossRef]

19. Turnhout, E.; Stuiver, M.; Klostermann, J.; Harms, B.; Leeuwis, C. New roles of science in society: Different repertoires of knowledge brokering. Sci. Publ. Policy 2013. [CrossRef]

20. Bielak, A.T.; Campbell, A.; Pope, S.; Schaefer, K.; Shaxson, L. From science communication to knowledge brokering: The shift from 'science push' to 'policy pull'. In Communicating Science in Social Contexts; Cheng, D., Claessens, M., Gascoigne, T., Metcalfe, J., Schiele, B., Shi, S., Eds.; Springer: Dordrecht, The Netherlands, 2008; pp. 201-226.

21. Hoppe, R. Scientific advice and public policy: Expert advisers' and policymakers' discourses on boundary work. Poiesis Prax. 2009, 6, 235-263. [CrossRef] [PubMed]

22. Hoppe, R. From 'knowledge use' towards 'boundary work': Sketch of an emerging new agenda for inquiry into science-policy interaction. In Knowledge Democracy; Veld, R.J., Ed.; Springer: Berlin/Heidelberg, Germany, 2010; pp. 169-186.

23. Michaels, S. Matching knowledge brokering strategies to environmental policy problems and settings. Environ. Sci. Policy 2009, 12, 994-1011. [CrossRef]

24. Schlierf, K.; Meyer, M. Situating knowledge intermediation: Insights from science shops and knowledge brokers. Sci. Publ. Policy 2013. [CrossRef]

25. Landry, R.; Amara, N.; Lamari, M. Utilization of social science research knowledge in Canada. Res. Policy 2001, 30, 333-349. [CrossRef]

26. Cash, D.W.; Clark, W.C.; Alcock, F.; Dickson, N.M.; Eckley, N.; Guston, D.H.; Jäger, J.; Mitchell, R.B. Knowledge systems for sustainable development. Proc. Natl. Acad. Sci. USA 2003, 100, 8086-8091. [CrossRef] [PubMed]

27. Cuppen, E.; Breukers, S.; Hisschemöller, M.; Bergsma, E. Q methodology to select participants for a stakeholder dialogue on energy options from biomass in the Netherlands. Ecol. Econ. 2010, 69, 579-591. [CrossRef]

28. Floor, J.R.; van Koppen, C.K.; Lindeboom, H.J. A review of science-policy interactions in the Dutch Wadden Sea-The cockle fishery and gas exploitation controversies. J. Sea Res. 2013, 82, 165-175. [CrossRef]

29. Seijger, C.; Dewulf, G.; Otter, H.; Van Tatenhove, J. Understanding interactive knowledge development in coastal projects. Environ. Sci. Policy 2013, 29, 103-114. [CrossRef]

30. Clark, W.C.; Tomich, T.P.; Van Noordwijk, M.; Guston, D.; Catacutan, D.; Dickson, N.M.; McNie, E. Boundary work for sustainable development: Natural resource management at the Consultative Group on International Agricultural Research (CGIAR). Proc. Natl. Acad. Sci. USA 2016, 113, 4615-4622. [CrossRef] [PubMed] 
31. Rosenkopf, L.; Nerkar, A. Beyond local search: Boundary-spanning, exploration, and impact in the optical disk industry. Strateg. Manag. J. 2001, 22, 287-306. [CrossRef]

32. Van Meerkerk, I. Boundary Spanning in Governance Networks: A Study about the Role of Boundary Spanners and Their Effects on Democratic throughput Legitimacy and Performance of Governance Networks. Ph.D. Thesis, Erasmus University Rotterdam, Rotterdam, The Netherlands, 5 September 2014.

33. Aldrich, H.; Herker, D. Boundary spanning roles and organization structure. Acad. Manag. Rev. 1977, 2 , 217-230. [CrossRef]

34. Fleming, L.; Waguespack, D.M. Brokerage, boundary spanning, and leadership in open innovation communities. Organ. Sci. 2007, 18, 165-180. [CrossRef]

35. Hoppe, R. Rethinking the science-policy nexus: From knowledge utilization and science technology studies to types of boundary arrangements. Poiesis Prax. 2005, 3, 199-215. [CrossRef]

36. Crona, B.I.; Parker, J.N. Learning in support of governance: Theories, methods, and a framework to assess how bridging organizations contribute to adaptive resource governance. Ecol. Soc. 2012, 17, 32. [CrossRef]

37. Buizer, J.; Cash, D.W.; National Research Council. Knowledge-Action Systems for Seasonal to Interannual Climate Forecasting: Summary of a Workshop; National Academies Press: Washington, DC, USA, 2005.

38. Williams, P. We are all boundary spanners now? Int. J. Public Sect. Manag. 2013, 26, 17-32. [CrossRef]

39. Moss, T.; Medd, W.; Guy, S.; Marvin, S. Organising water: The hidden role of intermediary work. Water Altern. 2009, 2, 16-33.

40. Meyer, M.; Kearnes, M. Introduction to special section: Intermediaries between science, policy and the market. Sci. Publ. Policy 2013, 40, 423-429. [CrossRef]

41. Mintzberg, H. The Strategy Concept I: Five Ps for Strategy. Calif. Manag. Rev. 1987, 11-24. [CrossRef]

42. Hennink, M.; Hutter, I.; Bailey, A. Qualitative Research Methods. Available online: https: / / books.google.com.hk/books?hl=en\&lr=\&id=zN70kC0E3XQC\&oi=fnd\&pg=PP2\&dq=Hennink, +M., +Hutter, +I.,+Bailey, +A.+Qualitative+research+methods\&ots=HXSdZDsBAw\&sig=0COWJPK8vw16Q4Y7W82QXOv-40\&redir_esc=y\#v=onepage\&q=Hennink\%2C\%20M.\%2C\%20Hutter\%2C\%20I. $\% 2 \mathrm{C} \% 20$ Bailey\%2C\%20A.\%20Qualitative\%20research\%20methods\&f=false (accessed on 12 October 2017).

43. Strydom, W.F.; Funke, N.; Nienaber, S.; Nortje, K.; Steyn, M. Evidence-based policymaking: A review. S. Afr. J. Sci. 2010, 106, 17-24. [CrossRef]

44. Runhaar, H.A.; Van der Windt, H.J.; Van Tatenhove, J.P. Productive science-policy interactions for sustainable coastal management: Conclusions from the Wadden Sea area. Environ. Sci. Policy 2016, 55, 467-471. [CrossRef]

(C) 2017 by the authors. Licensee MDPI, Basel, Switzerland. This article is an open access article distributed under the terms and conditions of the Creative Commons Attribution (CC BY) license (http:/ / creativecommons.org/licenses/by/4.0/). 